\author{
Jean-Michel Jeannin
}

\section{Einleitung}

Beim Teestrauch Camellia sinensis handelt es sich um einen immergrünen, stark verzweigten kleinen Baum aus der Familie der Teegewächse, der in Kultur strauchförmig gezogen und zurückgeschnitten wird. Er dürfte ursprünglich aus Assam (Hinterindien) stammen, ist heute aber in ganz Südostasien verbreitet $[1,3]$.

\section{Verwendung}

Der Tee wird vorherrschend als Aufgussgetränk verwendet. Dazu werden die jungen Triebe (1 Knospe und 2 Blätter) geerntet, getrocknet und geschnitten. Je nach Verarbeitung erhält man Grüntee oder Schwarztee $[1,2]$. Parfümierter Schwarztee erhält sein Aroma von der Bergamotte (Citrus bergama), einer anderen exotischen Heilpflanze. Teebeutel werden volkstümlich zum Abwaschen des Sonnenbrands, als Kompressen gegen Kopfschmerzen oder zur Behandlung von müden Augen verwendet. In China wird der Tee als Stimulans, Diuretikum, Stomachikum und Expektorans sowie zur Behandlung der Dysenterie verabreicht. In Indien wird der Saft der Blätter zur Blutstillung von Verletzungswunden verwendet [3].

\section{Phytochemie}

Tee enthält $1-5 \%$ Koffein und Theobromin, Theophyllin, Dimethylxanthin, Xanthin, Adenin sowie 5-27\% Polyphenole (Catechin, Epigallocatechin und Epigallocatechingallat sowie Quercetin, Quercitrin und Rutin). Tee enthält auch 4-16,5\% Fett, Sterole und Vitamin C [3], ferner Theasapo-

\title{
Exotische Heilpflanzen (8)
}

\author{
Camellia sinensis (L.) Kuntze (Theaceae)
}

nin E1, Theasaponin E2 und Camelliasaponin [4]. Die Varietät C. sinensis var. Assamica enthält die spezifischen Assamsaponine A-I [4]. Zur Gewinnung von Schwarztee werden die gerollten Blätter eine bestimmte Zeit an der Luft gelagert, wobei blatteigene Polyphenoloxidasen und Peroxidasen für die charakteristische Veränderung der Farbe und des Aromas verantwortlich sind [2]. Zur Gewinnung von Grüntee wird dieser Prozess mittels Dampfbehandlung vor dem Rollen der Blätter verhindert. Grüntee enthält etwas mehr Polyphenole als der Schwarztee, weshalb er bitterer schmeckt. Insgesamt sind beide Teearten ungefähr gleich zusammengesetzt; der Koffeingehalt ist in beiden Teearten derselbe [3]. Tee enthält zudem die Aminosäure Theanin [5].

\section{Aktuelle Forschung}

Der regelmässige Konsum von Grüntee senkte den Gesamtcholesterolspiegel, nicht aber den Triglycerid- und den High-density-lipoprotein-Cholesterolspiegel [6]. Die Sterblichkeit nach akutem Herzinfarkt war bei Teetrinkern umso niedriger, je grösser die konsumierte Menge Tee war [7].

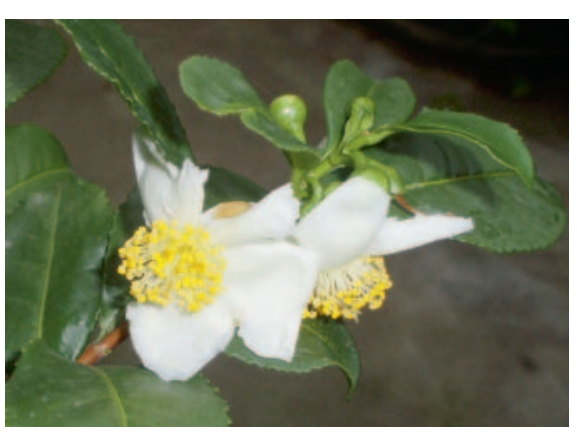

Abb. 1. Camellia sinensis var. Assamica. Basel, Botanischer Garten, 2011.
Grüntee senkte die Sterblichkeit ganz allgemein, mit Ausnahme der Mortalität an Krebs [8]. Theanin vermag als isolierte Substanz den Blutdruck zu senken [5]; für Theasaponin E1 wird eine magenschützende Wirkung postuliert [4].

\section{Literatur}

1 Stöcklin J: Tee, Schwarztee. Text zur Ausstellung «Wegzehrung». Universität Basel, 1996.

2 Engelhardt UH: Häufig gestellte Fragen zu Tee. Wissenschaftlicher Informationsdienst Tee, 2006.

3 Leung AY, Forster S: Encyclopedia of Common Natural Ingredients, ed 2. New York, John Wiley \& Sons, 1996, pp 489-492.

4 Murakami $\mathrm{T}$, et al: Bioactive saponins and glycosides. XV. Saponin constituents with gastroprotective effect from the seeds of tea plant, Camellia sinensis L. var. assamica Pierre, cultivated in Sri Lanka: structures of assamsaponins A, B, C, D, and E. Chem Pharm Bull 1999;47:1759-1764.

$\checkmark 5$ Desai MJ, et al: Analysis of derivatized and underivatized theanine enantiomers by highperformance liquid chromatography/atmospheric pressure ionization-mass spectrometry. Rapid Comm Mass Spectrom 2004;18:251-256.

6 Kono S, et al: Green tea consumption and serum lipid profiles: a cross-sectional study in northern Kyushu, Japan. Prev Med 1992;21:526-531.

7 Mukamal KJ, et al: Tea consumption and mortality after acute myocardial infarction. Circulation 2002;105:2476-2481.

8 Kuriyama S, et al: Green tea consumption and mortality due to cardiovascular disease, cancer, and all causes in Japan. JAMA 2006;296:12551265.

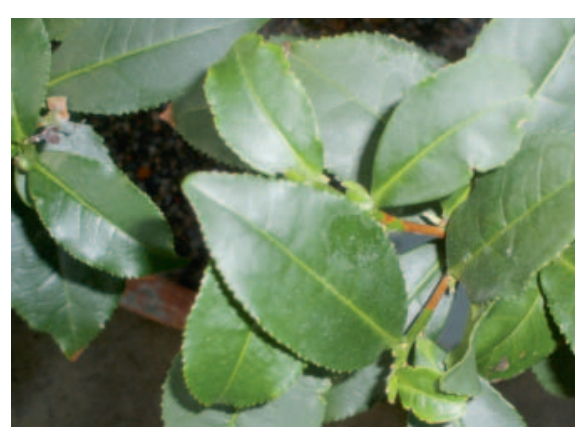

Abb. 2. C. sinensis. Basel, Botanischer Garten, 2011.

\section{KARGER}

Fax +497614520714 Information@Karger.d www.karger.com
() 2011 S. Karger GmbH, Freiburg
Dipl. med. biol. Jean-Michel Jeannin Holeestrasse 43, 4054 Basel, Schweiz

Tel. +41 61-4215991, Fax -4230313

jmjeannin@dataworks.ch 